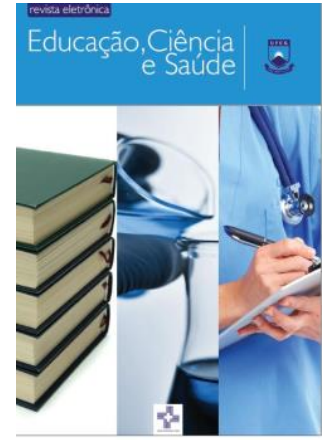

EDUCAÇÃO CIÊNCIA E SAÚDE

http://dx.doi.org/10.20438/ecs.v8i1.369

\title{
PRIMEIROS SOCORROS EM AMBIENTE ESCOLAR: UMA REVISÃO INTEGRATIVA
}

\author{
Rute Helly da Costa Maciel ${ }^{1}$, Allana Petrúcia Medeiros de Miranda ${ }^{1}$, Isadora \\ Caroline Pereira Sena de Carvalho ${ }^{1}$, Júlio Rodrigues de Avelar ${ }^{1}$, Letícia Moura \\ Ribeiro Barbosa ${ }^{1}$, Adriana Montenegro de Albuquerque ${ }^{2}$ \\ ${ }^{1}$ Curso de Bacharelado em Enfermagem, Unidade Acadêmica de Enfermagem, Universidade \\ Federal de Campina Grande, Cuité-PB, Brasil. \\ 2 Profa Unidade Acadêmica de Enfermagem, Universidade Federal de Campina Grande, Cuité, \\ PB, Brasil. \\ Email para correspondência: rutehellyc@gmail.com
}

\section{Resumo}

\begin{abstract}
Primeiros socorros são procedimentos prestados à vítima, capazes de estabilizar os sinais vitais e evitar complicações. Habilitar estudantes e funcionários é fundamental para a prevenção de acidentes em crianças nas escolas. Objetivouse sintetizar os principais estudos com intervenções de educação em saúde sobre primeiros socorros no ambiente escolar. Trata-se de uma revisão integrativa realizada nas bases de dados Medline, Science Direct, Pubmed, LILACS e Bdenf, no periódo de outubro a novembro de 2020 que resultou em 14 artigos após aplicação dos critérios de elegibilidade. Identificam-se cinco estudos desenvolvidos no Brasil, 11 artigos apontaram nível IV em evidência científica e seis desses, foram publicados em 2017. Ressalta-se que as intervenções de educação em saúde acerca de primeiros socorros nos ambientes escolares, combinadas de forma teórico-práticas, se mostraram satisfatórias quanto aos seus resultados. Salienta-se melhora significativa no conhecimento da temática com professores, funcionários e alunos, tornando-os aptos a prestarem primeiros socorros em situações de incidentes/acidentes no ambiente escolar.
\end{abstract}

Palavras-chave: primeiros socorros, educação em saúde, educação.

\begin{abstract}
First aid is a procedure provided to the victim, which is capable of stabilizing vital signs and preventing further complications. Empowering students and staff is essential for preventing accidents at school. The purpose of this article is to synthesize the main studies with health education interventions on first aid in the school environment. This integrative review used the following databases: Medline, Science Direct, Pubmed, LILACS and Bdenf. The research took place between October and November of 2020 and resulted in 14 articles after applying the eligibility criteria. 5 studies were identified in Brazil, 11 articles indicated level IV in scientific evidence and 6 of these were published in 2017. It is noteworthy that health education interventions about first aid in school environments, combined in a theoretical-practical way, were satisfactory in terms of their results. Significant improvement in knowledge of the subject with teachers, employees and students,
\end{abstract}

Educ. Ci. e Saúde, v. 8, n. 1, p. 63-77, (jan./jun.), 2021 
making them able to provide first aid in situations of incidents/accidents in the school environment.

Keywords: first aid, health education, education.

\section{Introdução}

A Educação em Saúde deve ser entendida como um instrumento de participação popular, no qual irão ser aplicados formas para questionar as práticas atuais e implementar o saber científico de acordo com as vivências pregressas de cada indivíduo. Logo, essa prática busca ofertar autonomia às pessoas frente ao seu próprio cuidado, sendo fundamental na prevenção de agravos e promoção da saúde (MESQUITA et al., 2017).

Ressalta-se que não é incomum encontrar casos de acidentes em escolas, seja eles com adultos ou crianças, de forma intencional ou não, podendo, muitas vezes, acarretar em lesões que perpetuam por toda vida ou gerar algum trauma psicológico. Sendo assim, primeiros socorros são procedimentos prestados à vítima, capazes de estabilizar os sinais vitais e evitar maiores complicações (COELHO, 2015).

Dessa forma, as ações de promoção à saúde nas escolas não devem ser dispensadas, visto que as crianças permanecem parte do seu dia nesse ambiente e estão constantemente, expostas às situações de agravos à saúde. Consequentemente, o ambiente escolar é um local propício para oferecer aos professores educação em saúse sobre noções básicas de primeiros socorros. Evidencia-se uma lacuna sobre a temática, visto que professores e funcionários não possuem capacitação adequada e, realizam procedimentos por meio do senso comum diante a alguma intercorrência (ZONTA et al., 2019).

Além disso, LUKAS et al. (2016) reafirmam que a capacitação dos professores é imprescindível, uma vez que os alunos absorvem mais o conhecimento quando a temática é ministrada por educadores, devido a sua habilidade de ensinar, obtendo assim melhores resultados. Ademais, Coelho (2019) ainda ressalta que a devida instrução sendo aplicada ao longo dos anos nas escolas, de forma simples e didática, por meio de simulados práticos, os estudantes podem adquirir um conhecimento eficaz frente a uma situação de urgência ou emergência, podendo estender essas habilidades teórico-práticas aos familiares. 
Sendo assim, objetivou-se sintetizar os principais estudos com intervenções de educação em saúde relacionados a primeiros socorros no ambiente escolar.

\section{Metodologia}

O estudo tratou-se de uma revisão integrativa, a qual é considerada uma pesquisa que possibilita a busca, a análise crítica e a síntese a respeito de uma determinada temática. Para elaboração da revisão, foram utilizadas seis etapas: 1) eleção da temática; 2) estabelecimento de critérios de exclusão e inclusão; 3) coleta de dados; 4) análise crítica dos artigos selecionados; 5) apresentação e discussão dos resultados e 6) apresentação da revisão integrativa (SOUZA; SILVA; CARVALHO, 2010).

Norteou-se esta pesquisa pela questão: Quais as produções científicas sobre primeiros socorros em ambiente escolar?

A estratégia de identificação e seleção dos estudos foi realizada por meio da busca de publicações nas bases de dados da Medical Literature and Retrivial System onLine (Medline), Science Direct, U. S. National Library of Medicine (Pubmed), Literatura Latino-Americana e do Caribe em Ciências da Saúde (LILACS) e Bases de Dados de Enfermagem (Bdenf) durante o mês de outubro de 2020, no qual utilizou-se os descritores: primeiros socorros (first aid), educação em saúde (health education), educação (education).

Os critérios de inclusão definidos foram: artigos disponibilizados na íntegra; publicados em português, inglês e espanhol; entre os anos de 2015 a 2019 e que respondam a questão norteadora. Como critérios de exclusão foram estabelecidos: artigos de revisão; dissertação, teses, artigos científicos repetidos nas bases de dados e artigos que não contemplassem a temática.

A utilização das escalas para classificar o nível de evidência em estudos tem a sua importância para determinar a eficácia de uma determinada intervenção realizada em um estudo de maneira padronizada. Desta forma, é possível perceber com facilidade qual resultado seria melhor recomendado para a prática. A escala utilizada para avaliar os estudos contém sete níveis, que se dividem a partir de: Nível 1 para revisão sistemática ou metanálise 
randomizados, nível 2 para um ensaio clínico randomizado,nível 3 para ensaio clínicos não randomizado, nível 4 para estudos de coorte e de caso-controle, nível 5 para o apanhado em formato de revisão sistemática de artigos descritivos e qualitativos, nível 6 quando a informaçã é fonte de apenas um estudo descritivo ou qualitativo e nível 7 para informações que tem origem a partir da opinião de profissionais (GALVAO, 2016).

Para a busca dos artigos que respondessem à questão norteadora da pesquisa, foram elegidas as palavras em inglês "first aid", "health" e "education", nos Descritores em Ciência da Saúde (DECs), combinados entre si por meio do operador booleano "AND", conforme descrito no Quadro 1.

Quadro 1 - Combinação dos descritores nas bases de dados. Cuité (PB), Brasil, 2020.

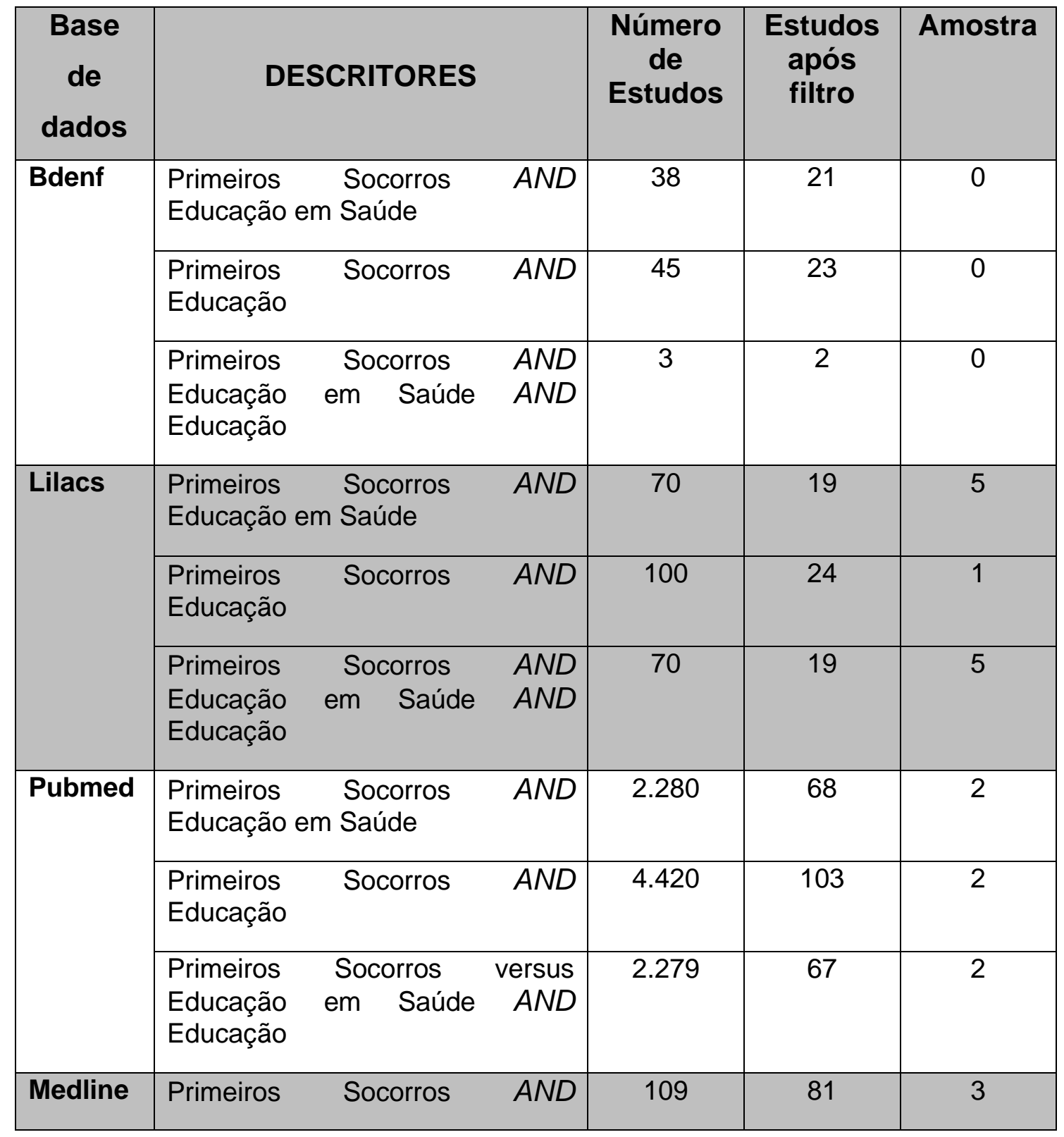




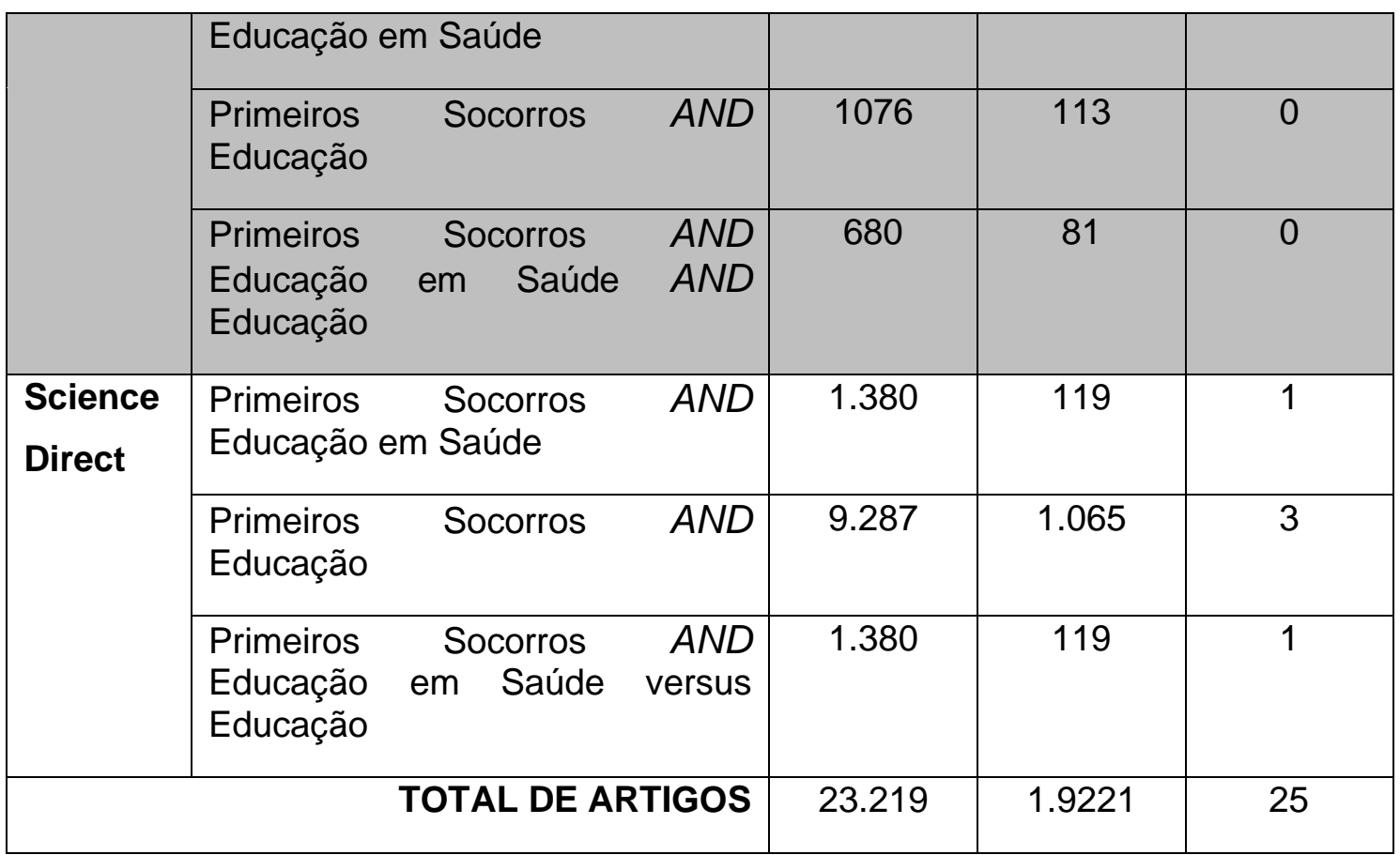

Identificam-se 23.219 publicações na primeira busca, destes, ao ser aplicado o primeiro filtro (ano, texto disponível na íntegra e idioma), restaramse 1.922 artigos. Após a leitura dos títulos e resumos, foi aplicado os critérios de exclusão, dos quais foram excluídos 1.893, resultando em uma amostra de 25 publicações científicas. Destes, ainda foram excluídos 11 artigos repetidos entre as bases de dados, no qual obteve-se como amostra final de 14 artigos de acordo com a Figura 1.

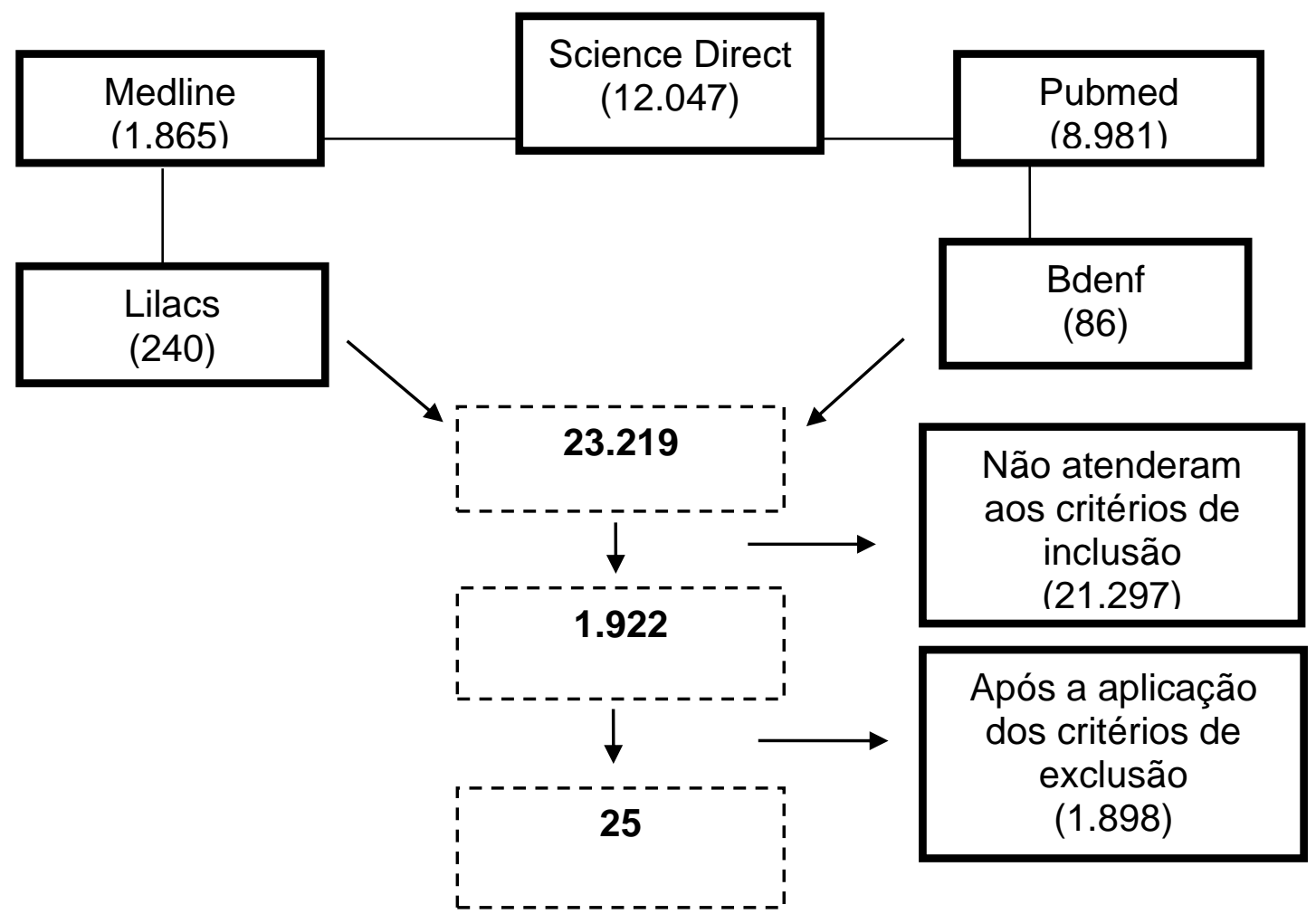




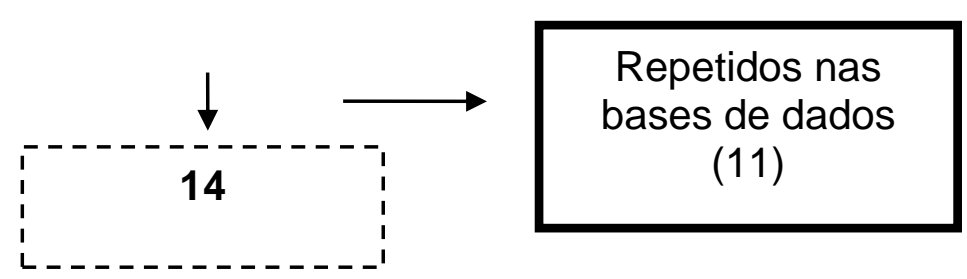

Figura 2- Resultados da pesquisa nas bases de dados. Cuité (PB), Brasil, 2020.

\section{Resultados e discussão}

No quadro 2 apresenta-se a síntese dos artigos quanto ao país, idioma, nome do periódico, Qualis, e o nível de evidências das publicações selecionadas na amostra desta pesquisa de revisão integrativa.

Quadro 2 - Síntese das publicações quanto ao país, idioma, revista, qualis e nível de evidência (NE). Cuité (PB), Brasil, 2020.

\begin{tabular}{|c|c|c|c|c|c|}
\hline № & País & Idioma & Periódico & Qualis & NE \\
\hline E1 & Brasil & Português & Revista Pensar a Prática & B2 & 4 \\
\hline E2 & Nigéria & Inglês & European Journal of Epilepsy & B1 & 4 \\
\hline E3 & Espanha & Espanhol & Enfermería Universitaria & B2 & 4 \\
\hline E4 & Alemanha & Inglês & $\begin{array}{c}\text { Official Journal of the } \\
\text { European Resuscitation } \\
\text { Council }\end{array}$ & $\mathrm{A} 1$ & 4 \\
\hline E5 & Hungria & Inglês & Emergency Medicine Journal & $\mathrm{B} 2$ & 4 \\
\hline E6 & $\begin{array}{l}\text { Coréia do } \\
\text { Sul }\end{array}$ & Inglês & PLOS ONE & A2 & 4 \\
\hline E7 & Espanha & $\begin{array}{c}\text { Espanhol } \\
\text { Inglês }\end{array}$ & Anales de Pediatria & B3 & 4 \\
\hline E8 & Brasil & Português & Revista Ciência Plural & B4 & 3 \\
\hline E9 & Brasil & Português & Acta Paulista de Enfermagem & $\bar{A} 2$ & 4 \\
\hline E10 & Brasil & Português & Revista Rene & B1 & 4 \\
\hline E11 & Austrália & Inglês & Journal of Asthma & $\mathrm{B} 2$ & 4 \\
\hline E12 & Austrália & Inglês & $\begin{array}{l}\text { Australian \& New Zealand } \\
\text { Journal of Psychiatry }\end{array}$ & A2 & 2 \\
\hline$\overline{E 13}$ & Brasil & Português & $\begin{array}{c}\text { Revista Latino-Americana de } \\
\text { Enfermagem }\end{array}$ & $\mathrm{A} 1$ & 4 \\
\hline E14 & China & Inglês & Public Health & B2 & 2 \\
\hline
\end{tabular}

Evidenciam-se cinco publicações desenvolvidas no Brasil, duas publicadas na Austrália e Espanha, e as outras foram dos países: Nigéria, Alemanha, Hungria, Corea do Sul e China. Em relação ao idioma das 
publicações, um foi publicado em duas linguas (inglesa e espanhola); cinco em português, um em espanhol e sete em inglês. Quanto aos periódicos, todas as 14 publicações apresentaram-se diferentes. Quanto aos Qualis, identificaramse cinco em Qualis B2, três em A2, duas cada um em Qualis B1 e A1 e uma em B3 e B4, respectivamente. Identifica-se os níveis 2, 3, e 4 de evidência, com predomínio do nível 4 em 11 publicações.

Salienta-se no quadro 3 a compilação dos dados das publicações referente ao título, objetivo e conclusão da amostra selecionada.

Quadro 3 - Síntese da produção científica (Estudo 1 - E1... Estudo 14 - E14). Cuité (PB), Brasil, 2020.

\begin{tabular}{|c|c|c|c|}
\hline № & Título & $\begin{array}{c}\text { Autor } \\
\text { Ano }\end{array}$ & Objetivo \\
\hline E1 & $\begin{array}{l}\text { Unidade Didática de } \\
\text { ensino dos Primeiros } \\
\text { Socorros r para } \\
\text { escolares: Efeitos do } \\
\text { aprendizado. }\end{array}$ & $\begin{array}{c}\text { COSTA et al., } \\
2015\end{array}$ & $\begin{array}{l}\text { Investigar o rendimento do } \\
\text { aprendizado e sua retenção, } \\
\text { sobre uma unidade didática } \\
\text { de ensino do conteúdo de } \\
\text { Primeiros Socorros para } \\
\text { escolares. }\end{array}$ \\
\hline E2 & $\begin{array}{l}\text { Effect of health } \\
\text { education on trainee } \\
\text { teachers' knowledge, } \\
\text { attitudes, and first aid } \\
\text { management of } \\
\text { epilepsy: } \\
\text { interventional study }\end{array}$ & $\begin{array}{l}\text { EZE et al., } \\
2015\end{array}$ & $\begin{array}{lccc}\text { Examinar } & 0 & \text { efeito } & \text { da } \\
\text { educação } & \text { em saúde } & \text { de } \\
\text { primeiros socorros atuante } & \text { socobre a epilepsia } & \text { em } \\
\text { sobre } & \text { professores } & \text { estagiários } & \text { na } \\
\text { Nigéria. } & & & \\
& & \end{array}$ \\
\hline E3 & $\begin{array}{lr}\text { Educación para } & \text { pasaludenprimerosauxil } \\
\text { lasal } & \text { ios dirigida al personal } \\
\text { docenter delámbito } \\
\text { escolar. }\end{array}$ & $\begin{array}{l}\text { MARTÍN, } \\
2015\end{array}$ & $\begin{array}{lr}\text { Avaliar a melhora do nível de } \\
\text { conhecimento } & \text { sobre } \\
\text { primeiros socorros } & \text { em } \\
\text { professores, após uma } & \text { intervenção educacional. } \\
\end{array}$ \\
\hline E4 & $\begin{array}{l}\text { Kids save lives: a six- } \\
\text { year longitudinal study } \\
\text { of schoolchildren } \\
\text { learning } \\
\text { cardiopulmonary } \\
\text { resuscitation: Who } \\
\text { should do the teaching } \\
\text { and will the effects } \\
\text { last? }\end{array}$ & $\begin{array}{c}\text { LUKAS et al., } \\
2015\end{array}$ & $\begin{array}{l}\text { Avaliar a atuação de } \\
\text { professores e médicos de } \\
\text { emergência como treinadores } \\
\text { de reanimação para crianças } \\
\text { durante um período de } 6 \\
\text { anos e investigar a retenção } \\
\text { do conhecimento e e } \\
\text { habilidades de alunos } \\
\text { treinados anualmente por } 3 \\
\text { anos. }\end{array}$ \\
\hline E5 & $\begin{array}{l}\text { 'The year of first aid': } \\
\text { effectiveness of a } 3 \text { - } \\
\text { day first aid }\end{array}$ & $\begin{array}{c}\text { BANFAl et } \\
\text { al., } 2017\end{array}$ & $\begin{array}{l}\text { Avaliar os efeitos de um } \\
\text { curso de primeiros socorros } \\
\text { de } 3 \text { dias para todos }\end{array}$ \\
\hline
\end{tabular}




\begin{tabular}{|c|c|c|c|}
\hline & $\begin{array}{l}\text { programme for } 7-14- \\
\text { year-old primary } \\
\text { school children. }\end{array}$ & & $\begin{array}{l}\text { grupos de idade de uma } \\
\text { escola primária ( } 7-14 \text { anos). }\end{array}$ \\
\hline E6 & $\begin{array}{l}\text { A preliminary } \\
\text { evaluation of the } \\
\text { training effects of a } \\
\text { didactic and } \\
\text { simulation-based } \\
\text { psychological first aid } \\
\text { program in students } \\
\text { and school counselors } \\
\text { in South Korea. }\end{array}$ & $\begin{array}{l}\text { LEE et al., } \\
2017\end{array}$ & $\begin{array}{lrr}\text { Examinar os } & \text { efeitos do } \\
\text { treinamento de } & \text { uma } \\
\text { abordagem didática } & \text { e } \\
\text { baseada em simulação do } \\
\text { programa de primeiros } \\
\text { socorros psicológicos. }\end{array}$ \\
\hline E7 & $\begin{array}{l}\text { A first step to teaching } \\
\text { basic life support in } \\
\text { schools: Training the } \\
\text { teachers }\end{array}$ & $\begin{array}{l}\text { LÓPEZ et al., } \\
2017\end{array}$ & $\begin{array}{l}\text { Avaliar quantitativamente a } \\
\text { qualidade das ações de } \\
\text { suporte básico de vida } \\
\text { realizadas por professores da } \\
\text { escola após um programa de } \\
\text { treinamento breve e simples. }\end{array}$ \\
\hline E8 & \begin{tabular}{lr}
\multicolumn{2}{l}{ Recurso educativo em } \\
primeiros & socorros no \\
processo & ensino- \\
aprendizagem & em \\
crianças de & uma \\
escola pública. &
\end{tabular} & $\begin{array}{l}\text { MESQUITA } \\
\text { et al., } 2017\end{array}$ & $\begin{array}{l}\text { Avaliar a efetividade de uma } \\
\text { estratégia de ensino- } \\
\text { aprendizagem baseada em } \\
\text { um recurso educativo para } \\
\text { identificação de } \\
\text { procedimentos de primeiros } \\
\text { socorros em alunos do } \\
\text { ensino fundamental de uma } \\
\text { escola pública. }\end{array}$ \\
\hline E9 & 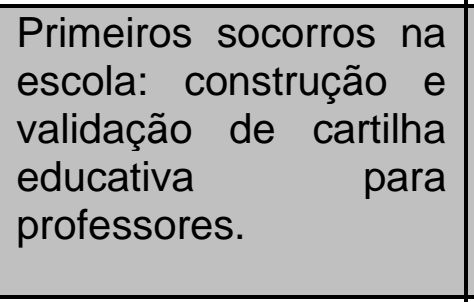 & $\begin{array}{l}\text { GALINDO } \\
\text { NETO et al., } \\
2017\end{array}$ & $\begin{array}{l}\text { Construir e validar uma } \\
\text { cartilha educativa para } \\
\text { professores da educação } \\
\text { infantil e ensino fundamental } \\
\text { I sobre primeiros socorros na } \\
\text { escola. }\end{array}$ \\
\hline E10 & $\begin{array}{l}\text { Primeiros socorros na } \\
\text { escola: treinamento de } \\
\text { professores } \\
\text { funcionários. }\end{array}$ & $\begin{array}{l}\text { CALANDRIM } \\
\text { et al., } 2017\end{array}$ & $\begin{array}{l}\text { Avaliar o conhecimento de } \\
\text { professores e funcionários } \\
\text { após um treinamento de } \\
\text { primeiros socorros. }\end{array}$ \\
\hline E11 & $\begin{array}{l}\text { Impact of scenario } \\
\text { based training on } \\
\text { asthma first aid } \\
\text { knowledge and skills in } \\
\text { school staff: an open } \\
\text { label, three-arm, } \\
\text { parallel-group } \\
\text { repeated measures } \\
\text { study. }\end{array}$ & $\begin{array}{l}\text { LUCKIE et } \\
\text { al., } 2018\end{array}$ & $\begin{array}{l}\text { Testar a hipótese de que o } \\
\text { treinamento baseado em } \\
\text { cenários é mais eficaz do que } \\
\text { o baseado somente em } \\
\text { conhecimento, } \\
\text { visandomelhorar } \\
\text { habilidades de primeiros } \\
\text { socorros voltados para a } \\
\text { asma, busca incluir diversos } \\
\text { funcionários da escola. }\end{array}$ \\
\hline $\mathrm{E} 12$ & $\begin{array}{l}\text { Helping adolescents to } \\
\text { better support their }\end{array}$ & $\begin{array}{l}\text { HART et al., } \\
2018\end{array}$ & $\begin{array}{l}\text { Avaliar um programa escolar } \\
\text { voltado para os Primeiros }\end{array}$ \\
\hline
\end{tabular}




\begin{tabular}{|c|c|c|c|}
\hline & $\begin{array}{l}\text { peers with a mental } \\
\text { health problem: } A \\
\text { cluster-randomised } \\
\text { crossover trial of teen } \\
\text { Mental Health FirstAid. }\end{array}$ & & $\begin{array}{l}\text { socorros de saúde mental } \\
\text { para adolescentes, } \\
\text { comparando-o a outro } \\
\text { programa de treinamento de } \\
\text { primeiros socorros físicos de } \\
\text { emergência correspondente. }\end{array}$ \\
\hline E13 & $\begin{array}{lr}\text { Autoconfiança } & \text { no } \\
\text { manejo das } \\
\text { intercorrências } & \text { de } \\
\text { saúde na escola: } \\
\text { contribuições } \\
\text { simulação in situ }\end{array}$ & $\begin{array}{l}\text { ZONTA et al., } \\
2019\end{array}$ & $\begin{array}{l}\text { Analisar as contribuições da } \\
\text { simulação in situ na } \\
\text { autoconfiança de professores } \\
\text { da educação infantil e } \\
\text { fundamental I com relação ao } \\
\text { manejo inicial das } \\
\text { intercorrências de saúde na } \\
\text { escola. }\end{array}$ \\
\hline E14 & $\begin{array}{l}\text { Effects of three } \\
\text { different first-aid } \\
\text { training methods } \\
\text { on knowledge } \\
\text { retention of caregivers } \\
\text { and teachers: a } \\
\text { randomized and } \\
\text { longitudinal cohort } \\
\text { study in } \\
\text { China. }\end{array}$ & LI et al., 2019 & $\begin{array}{l}\text { Avaliar os efeitos do } \\
\text { treinamento de primeiros } \\
\text { socorros pediátricos e a } \\
\text { retenção de conhecimento } \\
\text { por parte dos cuidadores e } \\
\text { professores avaliados. }\end{array}$ \\
\hline
\end{tabular}

Quanto ao ano de publicação dos 14 artigos, seis foram publicadas em 2017, quatro em 2015, e entre 2018 e 2019 foram dois artigos em cada ano. Utilizou-se o verbo "avaliar" nos objetivos de 8 artigos publicados, "examinar" em dois, e os verbos "investigar", "analisar", "construir e validar" nos outros quatro artigos.

Evidenciam-se sete publicações que nos seus títulos apresentam a palavra "primeiros socorros", dentre os estudos E1, E3, E5, E8, E9, E11 e E14. Dentre a amostra, os artigos E6, E7, E11 e E14 fizeram treinamento com os participantes, enquanto que os estudos E1, E2 e E8 realizaram uma intervenção educativa.

Realizar capacitações em emergências dentro do ambiente escolar possibilita que as medidas de primeiros socorros sejam realizadas o mais rápido possível, evitando complicações e possíveis sequelas, tornando assim o ambiente mais seguro. Sendo assim, é necessário que os treinamentos sejam permanentes, nos quais os conteúdos devam ser apresentados visualmente e também com a realização de demonstrações práticas, em que o público alvo 
participe de forma ativa, a fim de avaliá-los não só pelo conhecimento cognitivo, mas pelas habilidades na prática de primeiros socorros (FELIX et al., 2017).

Estudo realizado na China, com participação de 1.282 profissionais, dentre cuidadores e professores de pré-escolas, demonstrou que todos os participantes melhoraram seus conhecimentos em relação aos primeiros socorros pediátricos após o treinamento. Esse treinamento consistiu-se em alocar aleatoriamente tais profissionais em três modelos didáticos. A avaliação do resultado foi realizada em 9 meses e 4 anos após a intervenção, em que os três métodos de treinamento não fizeram diferença em relação a retenção de conhecimentos a longo prazo, ou seja, os resultados foram semelhantes em 9 meses ou 4 anos (LI et al., 2020).

Pesquisadores ressaltam a importância da construção de instrumentos de forma a garantir a introdução dos conteúdos de primeiros socorros dentro da escola, com um aspecto mais formal e fazendo com que se encaixem na carga horária dos alunos, com o intuito de construir uma relação de ensino e aprendizagem que valorize a metodologia didática e que haja a aplicação do conteúdo, e o mais importante, a sua avaliação (ALVES et al., 2015).

Estudo com 81 professores da primeira infância, ensino básico e secundário, demonstrou que ao fim do treinamento, os profissionais melhoraram significativamente em todas as variáveis analisadas. Além disso, os professores, sem formação prévia, foram capazes de executar a sequência de Suporte Básico de Vida (SBV) com qualidade, com ressalvas para a compressão torácica e a taxa média de compressão. Outro ponto abordado no estudo, é que mesmo os professores que não foram expostos a treinamentos anteriores de suporte de vida, conseguem se beneficiar de um treinamento desse tipo, adiquirindo capacidade de repassar os conhecimentos aos seus alunos (LÓPEZ et al., 2018).

Na mesma temática, um estudo de seis anos, incluindo a participação de 261 alunos a partir de 10 anos realizado na Alemanha, com o intuito de avaliar a aprendizagem de Ressuscitação Cardiopulmonar (RCP) em idade escolar. Independente das instruções terem sido ministradas por professores treinados ou médicos de emergência, o conhecimento dos alunos acerca da temática 
aumentou. Com o estudo, foi possível observar que após os treinamentos, os alunos conseguiram dominar de forma satisfatória as habilidades de suporte básico de vida, com ênfase na RCP (LUKAS et al., 2016).

Considera-se que não é fácil levar educação em saúde sobre ventilação mecânica para crianças. Entretanto, a compressão torácica contínua é a parte mais importante da RCP. As diretrizes de ressuscitação do European Resuscitation Council (ERC) sugerem que, se as pessoas não tiverem treinamento em respiração de resgate, devem realizar apenas a compressão torácica. Assim, o treinamento em RCP deve ser iniciado aos 10 anos de idade, pois por mais que a maioria dessas crianças não consiga realizar de forma eficaz, elas podem aprender alguns aspectos da reanimação, como a avaliação da respiração e a posição correta das mãos (BENFAl et al., 2017).

Outro estudo experimental, realizado na Espanha, objetivou avaliar os efeitos de uma intervenção educativa para professores sobre primeiros socorros com ênfase em acidentes escolares. Com o estudo, foi possível observar que os professores apresentaram algum déficit no conhecimento acerca de primeiros socorros antes da aplicação da intervenção. Após a intervenção, os participantes foram capazes de aumentar seus níveis de conhecimento em relação a temática. Tal intervenção procurou fornecer aos professores os conhecimentos básicos sobre os acidentes mais comuns que podem ocorrer em um ambiente escolar e situações de urgência e emergência, bem como as ações que podem e devem realizar nesses casos (MARTíN et al., 2015).

Em simulação in situ, ou seja, realizada no ambiente de trabalho, foi observado que os professores que não haviam tido a experiência de vivenciar intercorrências de saúde ao longo de suas vidas, apresentaram maior diferença de escore de autoconfiança após a simulação, e isso é explicado pelos baixos escores no mesmo quesito na pré simulação. Esse resultado pode ser um indicativo de que há benefícios nas intervenções educativas realizadas entre professores que não possuem experiências prévias, o que reforça 0 pressuposto de que repetidas experiências tendem a melhorar a autoconfiança (ZONTA et al., 2019). 
Estudo realizado na Nigéria buscou examinar o efeito da educação no manejo de primeiros socorros para alunos com epilepsia em professores estagiários. Participaram 226 professores estagiários, e foram aplicados questionários e palestras sobre o assunto. Antes da aplicação, a maioria dos entrevistados havia lido sobre a epilepsia, e embora reconhecessem as suas manifestações, não conseguiam identificar as causas. Observou-se que 100 $(44,2 \%)$ participantes tinham pouco conhecimento sobre epilepsia no início do estudo. Identificou-se aumento significativo no gerenciamento de habilidade, atitudes e conhecimento em primeiros socorros acerca da epilepsia (EZE et al., 2015).

Ressalta-se estudo com funcionários de uma escola primária, em Sidney (Austrália), com o objetivo de educar esses funcionários sobre o manejo de primeiros socorros em asma. Os conhecimentos que os participantes possuíam sobre o tema melhoraram significativamente após a intervenção de educação em saúde, evidenciando a capacidade dos participantes de prestarem os primeiros socorros à crianças com asma. Ao fim do estudo, foi possível constatar que as pessoas que receberam treinamento sobre primeiros socorros em asma em uma avaliação prática e individual têm resultados mais satisfatórios que palestras didáticas (LUCKIE et al., 2018).

A forma de abordar a prática de educação em saúde deve mostrar o ser humano como protagonista de todo esse processo de ensino-aprendizagem, fazendo com que assim se torne mais fácil a sua compreensão acerca do tema abordado. Diante disso, algumas ferramentas podem ser utilizadas para abordar a temática, a exemplo de dinâmicas de grupos e outros recursos educativos para incentivar os participantes a incluir suas emoções, experiências de vida, críticas, contribuindo de forma direta para a construção da aprendizagem (MARQUES et al., 2017).

\section{Conclusão}

Diante do exposto, é possível concluir que as intervenções de educação em saúde acerca de primeiros socorros nos ambientes escolares se mostraram satisfatórias quanto aos seus resultados. $\mathrm{Na}$ totalidade dos estudos analisados, tanto professores, como funcionários e alunos, demostraram uma melhora 
significativa nos conhecimentos e práticas de como agir em situações de urgência e emergência.

Nesse sentido, pode-se observar a importância da educação em saúde de primeiros socorros em escolas, visto que a comunidade escolar apresentou déficit desse conhecimento antes da aplicação das oficinas. Destarte, a necessidade de capacitação dos profissionais da educação, uma vez que os alunos demonstraram maior absorção da temática quando se é ministrada por professores. Sendo assim, com a devida orientação e aplicação de seminários teórico-práticos, há o aumento na autonomia dos estudantes e profissionais da educação frente a prevenção de agravos.

Por fim, destaca-se a necessidade de realizar mais estudos voltados para a temática, com o intuito de fortalecer as evidências já existentes e, assim, prestar assistência eficaz frente às intercorrências que demandem o uso de primeiros socorros.

\section{Referências}

BANFAI, B. et. al. 'The year of first aid': Effectiveness of a 3-day first aid programme for 7-14-year-old primary school children. Emergency Medicine Journal, v. 34, n. 8, pag. 526-532, 2017. Disponível em: https://pubmed.ncbi.nlm.nih.gov/28420689/ Acesso em: 20 out. de 2020 .

CALANDRIM, L. et. al. First aid at school: teacher and staff training. Revista da Rede de Enfermagem do Nordeste, v.18, n.3, 2017. Disponível em: http://periodicos.ufc.br/rene/article/view/20045. Acesso em: 20 out. de 2020.

COSTA, C. W. et. al. Unidade Didática De Ensino Dos Primeiros Socorros Para Escolares: Efeitos Do Aprendizado. Pensar a Prática, v. 18, n.2, pag. 338-349, 2018. Disponível em: https://revistas.ufg.br/fef/article/view/30205. Acesso em: 20 de out. de 2020.

COELHO, J. P. S. L. ENSINO DE PRIMEIROS SOCORROS NAS ESCOLAS E SUA EFICÁCIA. Revista Científica do Itpac, Araguaína, v. 8, n. 1, jan. 2015. Disponível em: https://assets.unitpac.com.br/arquivos/Revista/76/Artigo 7.pdf. Acesso em: 02 nov. 2020.

GALINDO, N. et. al. Primeiros socorros na escola: construção e validação de cartilha educativa para professores. Acta Paulista de Enfermagem, São Paulo, v 30, n,1, pag. 87-93, 2017. Disponível em: https://pesquisa.bvsalud.org/portal/resource/pt/biblio837835. Acesso em 20 out. de 2020.

GALVÃO, C. M. Níveis de evidência. Acta Paul Enferm., v. 19, n. 2, p. 5-5, fev. 2006. Disponível em: $<$ https://acta-ape.org/article/niveis-de-evidencia/ $>$. Acesso em 25/11/2020. 
HART, L. M. et al. Helping adolescents to better support their peers with a mental health problem: A cluster-randomised crossover trial of teen Mental Health First Aid. Australian \& New Zealand Journal Of Psychiatry, Austrália, v. 52, n. 7, p. 638651, fev. 2018. Disponível em: https://doi.org/10.1177/0004867417753552. Acesso em: 22 out. 2020.

LEE, J. S. et. al. A preliminary evaluation of the training effects of a didactic and simulation-based psychological first aid program in students and school counselors in South Korea. Plus One, v. 12, n. 7, pag. 1-13, 2017. Disponível em:

https://journals.plos.org/plosone/article?id=10.1371/journal.pone.0181271. Acesso em 20 out. de 2020 .

LI, F. et al. Effects of three different first-aid training methods on knowledge retention of caregivers and teachers: a randomized and longitudinal cohort study in china. Public Health, [S.L.], v. 178, p. 97-104, jan. 2020. Elsevier BV.

http://dx.doi.org/10.1016/j.puhe.2019.08.021. Disponível em: https://doi.org/10.1016/j.puhe.2019.08.021. Acesso em: 22 out. 2020.

LÓPEZ, M. P. et al. A first step to teaching basic life support in schools: training the teachers. Anales de Pediatría (English Edition), [S.L.], v. 89, n. 5, p. 265-271, nov. 2018. Elsevier BV. http://dx.doi.org/10.1016/i.anpede.2018.06.002. Disponível em: https://www.sciencedirect.com/science/article/pii/S2341287918301182. Acesso em: 16 out. 2020.

LUKAS, R. P. et al. Kids save lives: a six-year longitudinal study of schoolchildren learning cardiopulmonary resuscitation. Resuscitation, [S.L.], v. 101, p. 35-40, abr. 2016. Elsevier BV. http://dx.doi.org/10.1016/j.resuscitation.2016.01.028. Disponível em: https://www.sciencedirect.com/science/article/pii/S0300957216000666.

Acessoem: 16 out. 2020.

LUCKIE, K. et al. Impact of scenario based training on asthma first aid knowledge and skills in school staff: an open label, three-arm, parallel-group repeated measures study. Journal Of Asthma, [S.L.], v. 56, n. 9, p. 973-984, 11 out. 2018. Informa UK Limited. http://dx.doi.org/10.1080/02770903.2018.1508471. Acesso em: 16 out. 2020.

MARTíN, R. A. et al. Educación para la salud em primeiros auxilios dirigida al personal docente del ámbito escolar. Enfermería Universitaria, [S.L.], v. 12, n. 2, p. 88-92, abr. 2015. Universidad Nacional Autonoma de Mexico.

http://dx.doi.org/10.1016/j.reu.2015.04.004. Disponível em:

https://www.sciencedirect.com/science/article/pii/S1665706315000056. Acesso em: 16 out. 2020.

MESQUITA, T. M. et. al. Recurso Educativo Em Primeiros Socorros No Processo Ensino-Aprendizagem Em Crianças De Uma Escola Pública. Revista Ciência Plural, v. 3, n. 1, p. 35-50, 10 jul. 2017. Disponível em:<

https://periodicos.ufrn.br/rcp/article/view/11464. Acesso em 20/10/20

SOUZA, M. T.; SILVA, M. D.; CARVALHO, R. Revisão integrativa: o que é e como fazer. Einstein (São Paulo), São Paulo, v. 8, n. 1, p. 102-106, 2010. Disponível em:https://www.scielo.br/scielo.php?script=sci abstract\&pid=S1679450820100001001 02\&lng=en\&nrm=iso\&tlng=pt . Acesso em 20/10/2020

ZONTA et. al. Self-confidence in the management of health complications at school: Contributions of the in situ simulation. Rev. Latino-Am. Enfermagem, Ribeirão Preto- 
SP, v. 27, 2019. Disponível em:< https://www.scielo.br/scielo.php?pid=S0104$11692019000100359 \&$ script=sci arttext\&tlng=en. Acesso em 20/10/20 